Review

\title{
Electrochemical Methods of Real Surface Area Determination of Noble Metal Electrodes - an Overview
}

\author{
M. Łukaszewski ${ }^{1}, M$. Soszko $^{2}, A$. Czerwiński $^{1,3, *}$ \\ ${ }^{1}$ Warsaw University, Department of Chemistry, Pasteura 1, 02-093 Warsaw, Poland \\ 2 Industrial Chemistry Research Institute, Rydygiera 8, 01-793 Warsaw, Poland \\ ${ }^{3}$ Faculty of Chemistry, Biological and Chemical Research Centre, University of Warsaw, Żwirki i \\ Wigury 101, 02-089 Warszawa \\ "E-mail: aczerw@chem.uw.edu.pl
}

doi: $10.20964 / 2016.06 .71$

Received: 1 March 2016 / Accepted: 3 April 2016 / Published: 4 May 2016

The electrochemical methods of real surface area determination of noble metal electrodes and their alloys are summarized. These methods utilize hydrogen adsorption, surface oxide reduction, double layer capacitance, adsorbed carbon monoxide stripping and underpotential deposition of metals. The principles, advantages and limitations of the methods are discussed. The examples of their use are shown. The comparison between various methods is presented.

Keywords: Real surface area; Noble metals; Alloys; Electrodes; Adsorption

\section{FULL TEXT}

(C) 2016 The Authors. Published by ESG (www.electrochemsci.org). This article is an open access article distributed under the terms and conditions of the Creative Commons Attribution license (http://creativecommons.org/licenses/by/4.0/). 